\title{
Development of an ultra-rapid diagnostic method based on heart-type fatty acid binding protein levels in the CSF of CJD patients
}

Yuki Matsui, Katsuya Satoh , Kazuo Mutsukura, Takuya Watanabe, Noriyuki Nishida, Hideo Matsuda, Masaichi Sugino, Susumu Shirabe, Katsumi Eguchi, and Yasufumi Kataoka

Yuki Matsui • Takuya Watanabe • Yasufumi Kataoka

Department of Pharmaceutical Care and Health Sciences, Faculty of Pharmaceutical

Sciences, Fukuoka University, 8-19-1 Nanakuma, Jonan-ku, Fukuoka 814-0180, Japan

Katsuya Satoh

First Department of Internal Medicine, Nagasaki University School of Medicine, 1-7-1

Sakamoto, Nagasaki 852-8501, Japan

And Department of Molecular Microbiology and Immunology, Graduate School of

Biomedical Science, Nagasaki University, 1-12-4 Sakamoto, Nagasaki 852-8523 Japan

Kazuo Mutsukura $\cdot$ Katsumi Eguchi

First Department of Internal Medicine, Nagasaki University School of Medicine, 1-7-1

Sakamoto, Nagasaki 852-8501, Japan

Noriyuki Nishida

Department of Molecular Microbiology and Immunology, Graduate School of

Biomedical Science, Nagasaki University, 1-12-4 Sakamoto, Nagasaki 852-8523 Japan

Hideo Matsuda. Laboratory of Immunobiology, Department of Molecular and Applied Bioscience, Graduate School of Biosphere Science, Hiroshima University, 1-4-4 Kagamiyama, Higashi-Hiroshima, Hiroshima 739-8528, Japan

Masaichi Sugino

First Department of Internal Medicine, Division of Neurology, Osaka Medical College, 2-7 Daigaku-machi, Takatsukishi, Osaka 569-8686, Japan 
Susumu Shirabe

Center for Community and Campus Health, Nagasaki University, 1-14 Bunkyo, Nagasaki 852-8521, Japan

Address correspondence and reprint requests to Dr. Katsuya Satoh, Department of Molecular Microbiology and Immunology, Graduate School of Biomedical Science, Nagasaki University, 1-12-4 Sakamoto, Nagasaki 852-8523 Japan

Tel: +81-95-819-7059 Fax: +81-95-819-7060

E-mail address: f1537@cc.nagasaki-u.ac.jp 
Word count: 3470

Summary of words: 250 words

Keywords: prion disease, H-FABP, CSF, 14-3-3 protein, Creutzfeldt-Jakob disease (CJD)

Number of References: 18

Number of figures: 4

Number of tables: 4

Number of Supplementary figures and tables: 2

Number of Color figures: 1

Short running title: Development of an ultra-rapid diagnostic method 


\section{Summary}

Aims: Creutzfeldt-Jakob disease (CJD) is a transmissible, fatal, neurodegenerative disease in humans. Recently, various drugs have been reported to be useful in the treatment of CJD; however, for such treatments to be useful it is essential to rapidly and accurately diagnose CJD.

Methods: 124 CJD patients and 87 with other diseases causing rapid progressive dementia were examined. Cerebral spinal fluid (CSF) from CJD patients was analyzed by $2 \mathrm{D}-\mathrm{PAGE}$ and the protein expression pattern was compared with that from healthy subjects. One of three CJD-specific spots was found to be fatty acid binding protein (FABP), and heart-type FABP (H-FABP) was analyzed as a new biochemical marker for CJD. H-FABP ELISA results were compared between CJD patients and patients with other diseases $(n=211)$. Visual readout accuracy of the Rapicheck ${ }^{\circledR}$ H-FABP test panel for CSF was analyzed using an independent measure of CSF H-FABP concentration. The distribution of H-FABP in the brains of CJD patients was examined by immunohistochemistry.

Results: ELISA sensitivity and specificity were $90.3 \%$ and $92.9 \%$, respectively, and Rapicheck ${ }^{\circledR}$ H-FABP sensitivity and specificity were $87.9 \%$ and $96.0 \%$, respectively. ELISA and Rapicheck ${ }^{\circledR}$ H-FABP assays provided comparable results for 14-3-3 protein and total tau protein. Elevated H-FABP levels were associated with an accumulation of abnormal prion protein, astrocytic gliosis, and neuronal loss in the cerebral cortices of CJD patients.

Conclusions: Rapicheck ${ }^{\circledR}$ H-FABP of CSF specimens enabled quick and frequent diagnosis of CJD. H-FABP represents a new biomarker for CJD distinct from 14-3-3 protein and total tau protein. 


\section{Introduction}

Transmissible spongiform encephalopathies (TSEs) or prion diseases are a group of invariably fatal neurodegenerative disorders affecting humans and animals (Aguzzi and Heikenwalder 2006); the number of such disorders is growing (Watts et al. 2006; Mallucci et al. 2004). At least four novel prion diseases, including human variant Creutzfeldt-Jakob disease (vCJD), sporadic fatal insomnia (sFI), bovine spongiform encephalopathy (BSE), and Nor98 in sheep, have been identified in the last ten years. In Japan, the number of iatrogenic CJD (iCJD) patients has been increasing, with the number of cases exceeding 100 by 2008, and BSE was recently identified adding to concerns regarding these diseases and their spread (Watts et al. 2006).

Diagnosis of sporadic CJD (sCJD) is based on neurological findings, Periodic sharp wave complexes (PSWCs) observed on an electro-encephalograph (EEG) and the presence of 14-3-3 protein in the cerebrospinal fluid (CSF) are considered reliable diagnostic markers for CJD (Brandel et al. 2000). Both of these measures are included in the diagnostic criteria for CJD supplied by the World Health Organization (WHO) (Brandel et al. 2000).

Previously reported CSF biomarkers for CJD include14-3-3 protein, total tau (t-tau) protein and S-100 protein. CSF levels of 14-3-3 protein and t-tau protein are influenced by neuronal loss, making them useful in the diagnosis of classical CJD, while S-100 protein levels in the CSF are influenced by activation of astrocytes and subsequent astrocytic gliosis, making it useful for the diagnosis of atypical CJD. Thus, many of the previously reported biomarkers for CJD reflect only one aspect of the disease, and there is a need to identify new biomarkers for CJD that reflect both the neuronal loss and the astrocytic gliosis. The analysis of CSF biomarkers in CJD patients can be a lengthy process and is associated with the risk of spreading the infectious particles. Indeed, Orru et al.(Orru et al. 2009) showed the presence of abnormal prion protein $\left(\mathrm{PrP}^{\mathrm{Sc}}\right)$ in the CSF of individuals with human variant $\mathrm{CJD}$, revealing the possibility of infectious particles in human CSF.

Therapies such as cerebroventricular infusion of pentosan polysulfate or orally administered quinacrine or flupirtine have recently been shown to be effective in patients with human prion diseases, including CJD. However, a clinical study of quinacrine in patients with human prion disease found that it did not significantly affect the clinical course (Collinge et al. 2009). Geschwind reported that clinical trials for human prion disease are difficult because sporadic CJD patients usually die within six months of disease onset, with many succumbing within the first two weeks after diagnosis (Geschwind et al. 2009). Thus, CJD patients should be treated immediately 
following diagnosis, and should not have to wait for extended periods of time for the results of a diagnostic test, highlighting a need for a simple and fast screening test.

The purpose of this study was to identify new CSF biomarkers for CJD in CSF using 2D polyacrylamide gel electrophoresis (2D-PAGE). Three new markers were identified by comparing CSF samples from CJD patients with those from healthy subjects. One of these markers was identified as fatty acid binding protein (FABP). FABP proteins comprise a family of small, highly conserved, cytosolic 14-15 kDa proteins, which are involved in fatty acid transport and metabolism. Four FABPs specifically distributed in the CNS have been described: myelin FABP, brain FABP, epidermal FABP and heart-type FABP (H-FABP) (Owada et al. 1996). Because human $\mathrm{H}-\mathrm{FABP}$ is an early plasma marker for acute myocardial infarction (AMI), we hypothesized that H-FABP could also indicate brain injury in CJD-infected patients.

We analyzed H-FABP levels in the CSF of CJD patients using an ELISA, the sensitivity and specificity of which were $90.3 \%$ and $92.9 \%$, respectively. High concentrations of H-FABP were seen even in CSF samples from CJD patients with undetectable levels of 14-3-3 protein and low levels of t-tau protein $(<1300 \mathrm{pg} / \mathrm{ml}$ : CJD cut-off data).

Recently, Hiura et al. reported the development of a new kit (Rapicheck ${ }^{\circledR}$ H-FABP) allowing the rapid estimation of H-FABP levels in serum (Hiura et al. 2005). Rapicheck ${ }^{\circledR}$ H-FABP consists of a one-step immunochromatography system and a rapid semi-quantitative test for human H-FABP. Rapicheck ${ }^{\circledR}$ H-FABP was developed for the detection of cardiac damage and the diagnosis of AMI. Using this kit, we analyzed H-FABP levels in CSF samples from CJD patients, achieving a sensitivity and specificity of $87.9 \%$ and $96.0 \%$, respectively. Thus, H-FABP represents a new biomarker for CJD and Rapicheck ${ }^{\circledR}$ H-FABP represents an economic diagnostic tool to aid in the early diagnosis of this disease. 


\section{METHODS}

\section{Subjects}

Patients with suspected CJD were recruited from the hospitals all over Japan for the purpose of biochemical assays on CSF. From more than 300 requests, we were able to perform a follow-up study of 124 patients with CJD, as determined by DWI. We classified the cases as sporadic CJD $(n=114)$, familial CJD $(n=7$; five cases resulting from a V180I mutation in the prion protein gene and two cases resulting from an M232R mutation in the prion protein gene), or iatrogenic CJD (dura-associated CJD; $\mathrm{n}$ $=3$ ).

For the control data, we collected CSF samples from 87 patients who suffered from one of the following disorders: dementia of Alzheimer's type (DAT) $(n=54$; male $=33$, female $=21)$, cerebrovascular disorders $(\mathrm{CVD})(\mathrm{n}=7$; male $=5$, female $=$ $2)$, Pick's disease ( $n=1$; male), Parkinson's disease $(P D)(n=5$; male $=4$, female $=1)$, corticobasal degeneration (CBD) $(n=2$; both female), Huntington's disease $(n=1$; male), frontotemporal dementia (FTD) $(n=1$; male), progressive supranuclear palsy (PSP) $(\mathrm{n}=3$; male $=2$, female $=1)$, Wernicke's encephalopathy $(\mathrm{n}=2$; both male), limbic encephalitis $(\mathrm{n}=3$; male $=1$, female $=2)$, amyotrophic lateral sclerosis (ALS) $(\mathrm{n}=4$; male $=2$, female $=2)$. We also obtained CSF from four healthy volunteers ( $\mathrm{n}$ $=4$; male $=2$, female $=2$ ) $($ Table 1$)$.

The numbers of patients of each type are shown in Table 1 . This study was approved by the Medical Ethics Committee of Nagasaki University School of Medicine and the participants provided written informed consent.

\section{Two-Dimensional Polyacrylamide Gel Electrophoresis (2D-PAGE) and Protein Identification}

CSF samples from CJD patients and healthy, neurologically intact patients were compared by 2D-PAGE to detect differentially expressed proteins. CSF from deceased patients was obtained at autopsy, and all patients were definite cases of CJD. CSF samples were collected by routine lumbar puncture. The samples were analyzed on 2D-PAGE gels as previously described (Cepek et al. 2007). Briefly, CSF proteins (45 $\mu \mathrm{g}$ ) were mixed with $10 \mu \mathrm{l}$ of $10 \%$ SDS w/v/2.3\% dithioerythritol (DTE) w/v, which had previously been heated to $95^{\circ} \mathrm{C}$ for $5 \mathrm{~min}$.

The 2D-PAGE was performed according to Laemmli (Laemmli 1970) using sample buffer produced by BioRad (CO, USA) and SDS polyacrylamide gels consisting of $12 \%$ $(\mathrm{w} / \mathrm{v})$ total acrylamide monomer. The focused gel strips were laid onto the top of the polymerized SDS gels and covered by a low-melting point agarose buffer $[1 \%(\mathrm{w} / \mathrm{v})$ 
low-melting agarose, $0.25 \% \mathrm{SDS}, 0.36 \mathrm{M}$ bis-tris, $0.16 \mathrm{M}$ bicine, trace bromphenol blue], which had previously been heated to melting temperature. After polymerization, gels were run in pairs at $24 \mathrm{~mA} / \mathrm{gel}$ at constant current at room temperature.

\section{Gel Staining and Analysis}

Proteins were detected by silver staining according to Rabilloud's methods (Rabilloud 1999). Stained gels were scanned and the image files were imported to the analysis software Imagemaster 3.1 (Amersham Biosciences).

\section{Detection of the $\boldsymbol{\gamma}$-isoform of 14-3-3 Protein and T-Tau Protein in CSF Samples}

CSF samples were collected, aliquoted, and stored at $-80^{\circ} \mathrm{C}$ until further use. All assays were performed simultaneously to avoid repeated freezing and thawing. Immunoassays for 14-3-3 protein in CSF were performed as previously described (Orru et al. 2009; Owada et al.; 1996; Hiura et al. 2005). Polyclonal antibodies specific for the $\gamma$-isoform of 14-3-3 protein were obtained from Immuno-Biological Laboratories (IBL) (18647; Gunma, Japan) and used at a dilution of 1:5000. All samples were analyzed using the same antibody to ensure comparable sensitivities. Protein detection was performed using an enhanced chemiluminescence detection kit (Amersham Buchler Company). Detection of t-tau protein in CSF samples was performed as previously described (Satoh et al. 2010; Satoh et al. 2007a; Satoh et al. 2007b) .All assays were performed by two independent researchers.

\section{CSF H-FABP concentration in CSF Samples}

The concentration of H-FABP in the CSF was measured using an ELISA kit (MARKIT-M HFABP Dainippon Pharmaceutical Co., Ltd., Osaka, Japan), in accordance with the manufacturer's instructions. We performed this assay on CSF samples from 211 patients. All assays were performed by two independent researchers.

\section{Rapicheck ${ }^{\circledR}$ H-FABP assay}

In accordance with the manufacturer's manual for Rapicheck ${ }^{\circledR}$ H-FABP (Dainippon Pharmaceutical Co. Ltd., Osaka, Japan), CSF (150 $\mu 1)$, samples were collected in tubes (Venues, Terumo, Tokyo, Japan) (Supplementary Figure 1-a) and placed onto the designated section of the test plate. The plate was incubated at room temperature for 15 minutes. We performed the Rapicheck ${ }^{\circledR}$ H-FABP assay according to the method described in a previously published report (Hiura et al. 2005). The appearance of an indicator test line (in addition to the quality control line) within 5 
minutes was graded as +3 (strongly positive); appearance of a test line within 15 minutes was graded as +2 (moderately positive); and the appearance of a weak test line within 15 minutes was graded as +1 (weakly positive). The absence of a test line at 15 minutes was reported as 0 (negative). All assays were performed by two independent researchers. (Supplementary Figure 1-b)

\section{Immunohistochemistry}

Immunohistochemistry was performed on eleven samples of brain tissue (frontal lobe, temporal lobe, occipital lobe, parietal lobe basal ganglia, caudate head, midbrain, pons, medulla, cerebellar lobules and dentate nucleus) from five patients with sporadic CJD. Brain tissue was fixed with $20 \%$ buffered formalin. Multiple tissue blocks were immersed in $95 \%$ formic acid overnight, and then embedded in paraffin. Histological examination was performed on 5-mm-thick sections. Selected sections were immunostained using the avidin-biotin-peroxidase complex $(\mathrm{ABC})$ method (Vector, Burlingame, CA, USA) with diaminobenzidine as the chromogen. After incubation for 60 minutes at room temperature with anti-H-FABP antiserum (dilution, 1:1000), anti-3F4 antiserum (dilution, 1:1000), which detects abnormal prion protein, and anti-S-100 protein antiserum (dilution, 1:5000), which detects astrocytes, an immunoperoxidase technique using a biotinylated goat anti-rabbit IgG as a secondary antibody and a peroxidase-conjugated avidin-biotin complex was performed according to the manufacturer's instructions (DAKO Co.). Peroxidase reactivity was then revealed using hydrogen peroxide and diaminobenzidine as a chromogenic substrate. As a control, preimmune serum from the immunized rabbit was used simultaneously on adjacent sections.

\section{Statistical Analysis}

We used SPSS version 11.0 software to perform all statistical analyses. Standard measures of diagnostic test validity were used to identify true-positive, true-negative, false-positive, and false-negative results. The H-FABP levels of 124 CJD patients and the remaining 87 patients with other diseases were used for these calculations (ROC analysis).The relationship between t-tau protein and H-FABP levels was statistically analyzed on the basis of Kendall and Spearman's coefficients using SPSS version 11.0 software. 


\section{RESULTS}

\section{Analysis of 2D-PAGE gels}

To delineate proteins that are differentially present in the CSF of CJD patients $(n=4)$ and healthy subjects $(n=4), C S F$ samples were separated by 2D-PAGE and the levels of all detectable protein spots (107 spots) were compared between the groups. (Figure 1-a) All spots were analyzed using Image Master software (Amersham Bioscience) and manually revised. Three hundred and ten out of 107 spots were identified; of these, 69 were matched to a reference gel. Three spots were found to be elevated in the CSF of CJD patients compared with healthy subjects. (Figure 1-b)

These spots of interest were excised for enzymatic cleavage and analysis by peptide mass fingerprinting using a MALDI-TOF mass spectrometer (PerSeptive Biosystems Voyager STR, Framingham, MA, USA). Proteins were identified by database searching. Two protein spots were identified as possibly being epidermal FABP (FABE), adipocytes FABP and heart-type FABP (H-FABP). We did not identify the expression of FABP and adipocytes FABP in mouse brain (data not shown).

\section{Analysis of 14-3-3 protein and t-tau protein levels in CSF samples}

CSF samples from 211 patients were assayed for the $\gamma$-isoform of 14-3-3 protein. In the CJD group, 14-3-3 protein was detected in all CSF samples (124 patients). By comparison, 14-3-3 protein was detected in only two non-CJD patients with DAT, one patient with CVD, two patients with Wernicke's encephalopathy, and three patients with limbic encephalitis among the 87 otherwise healthy control subjects. The sensitivity and specificity of this assay for $14-3-3$ protein in CJD patients were $82.2 \%$ and $90.8 \%$, respectively (Figure 4) .

CSF levels of t-tau protein were determined in 211 patients, and significant differences were observed among individuals (Table 1). The level of t-tau protein was the greatest in the CJD group, ranging from $1,248 \mathrm{pg} / \mathrm{ml}$ to $16,087 \mathrm{pg} / \mathrm{ml}$ (mean \pm S.D.: $7,174 \pm 6,558 \mathrm{pg} / \mathrm{ml})$. In the DAT group, t-tau protein levels ranged between $117 \mathrm{pg} / \mathrm{ml}$ and $1389 \mathrm{pg} / \mathrm{ml}$ (mean \pm S.D.: $387.37 \pm 275.5 \mathrm{pg} / \mathrm{ml})$. The CVD group showed levels similar to those in the DAT group, with a range of 172-1300 pg/ml (mean \pm S.D.: 623.4 $\pm 612.4 \mathrm{pg} / \mathrm{ml}$ ). Therefore, compared with all other patients, CJD patients expressed higher levels of t-tau protein $(\mathrm{p}<0.01)$; their levels were also higher than those in the CVD and DAT groups specifically $(\mathrm{p}<0.05)$. (Table 1$)$ The sensitivity and specificity of t-tau protein in CJD patients were $87.9 \%$ and $85.1 \%$, respectively (Figure 4 ). 


\section{H-FABP ELISA of CSF}

Significant differences in H-FABP levels existed among the 12 groups of patients (Figure 2-a). H-FABP levels were highest in the CJD group, with a range of 3,048-43,109 pg/ml (mean \pm S.D.: 11,798 \pm 9,462 pg/ml) (Figure 2-a and 2-b; Table 1). In comparison, the levels of H-FABP protein in the DAT group ranged from $1975 \mathrm{pg} / \mathrm{ml}$ to $5723 \mathrm{pg} / \mathrm{ml}$ (mean \pm S.D.: $2786 \pm 911 \mathrm{pg} / \mathrm{ml})$. Compared with all other patients, CJD patients expressed higher levels of H-FABP $(p<0.01)$, and their levels were also higher than those in the CVD and DAT groups specifically $(\mathrm{p}<0.05)$ (Figure 2-b). Therefore, the cut-off value for the ELISA for H-FABP in CJD patients, determined by ROC analysis using SPSS version 11.0, was 3,500 pg/ml. (Figure 2-c) The sensitivity and specificity of H-FABP in CJD patients were 90.3\% and 92.9\%, respectively (Figure 4).

\section{Further analysis of CSF biomarkers in CJD patients}

We analyzed the CSF levels of 14-3-3 protein, t-tau protein and H-FABP in 124 CJD patients. Altogether, 112 patients were found to be H-FABP-positive. 95 patients with H-FABP-positive CSF were also positive for 14-3-3 protein and t-tau protein in the CSF. 5 patients were negative for both of these proteins (Table 2-a); these patients included two sporadic CJD cases and three familial CJD cases (resulting from a V180I mutation (Table 2-b). We also analyzed chronological samples from 10 patients, revealing a gradual increase in H-FABP level as detected by ELISA (supplementary Figure 2-a,b). The chronological stages of CJD have not been clearly defined; therefore, we used the stages defined by Satoh et al. (Satoh et al. 2010; Satoh et al. 2007a), as follows: the early stage was within 6 weeks of onset, the middle stage was from week 7 to the onset of akinetic mutism, and the end stage was after the onset of akinetic mutism.

\section{Rapicheck ${ }^{\circledR}$ H-FABP Analysis of CSF samples}

H-FABP protein levels in CSF samples from all 211 patients were measured using the Rapicheck ${ }^{\circledR}$ system, which detected H-FABP in all CJD patients $(n=124)$. In the non-CJD groups, the Rapicheck ${ }^{\circledR}$ system detected H-FABP protein in one patient with DAT, one with CVD, two with Wernicke's encephalopathy, and three with limbic encephalitis. All non-CJD patients positive for H-FABP using the Rapicheck ${ }^{\circledR}$ system showed high levels of H-FABP by ELISA. The sensitivity and specificity of H-FABP in CJD patients were $87.9 \%$ and $96.0 \%$, respectively (Figure 3,4)

CJD is estimated to affect between 0.5 and 1.5 cases per million people per year; therefore most clinics would experience just 1-3 patients per year. The ELISA for 
H-FABP is an unsuitable method for clinical examinations because ELISA provides for the simultaneous processing of numerous CSF samples. Moreover the price of ELISA for H-FABP for one patient or two patients is about one hundred times as expensive as that of the Rapicheck ${ }^{\circledR}$ H-FABP system. The Rapicheck ${ }^{\circledR}$ H-FABP system enables the assessment of one specimen at a time. As well, the Rapicheck ${ }^{\circledR}$ H-FABP system should be available in many hospitals in Japan because it is a useful and popular diagnostic kit for acute myocardial infarction and angina pectoris.

It is clear that ELISA for H-FABP is unsuitable for the small numbers of possible cases in small urban centers, places where the Rapicheck ${ }^{\circledR}$ H-FABP assay is more appropriate.

The cut-off level for the Rapicheck ${ }^{\circledR}$ H-FABP system was determined to be 6,200 $\mathrm{pg} / \mathrm{ml}$, approximately the same as that determined by Hiura et al (Hiura et al. 2005). However, there are no reports of the relationship between the levels of CSF H-FABP detected by ELISA and those detected by Rapicheck ${ }^{\circledR}$ assay.

\section{Neuropathological analysis of H-FABP staining in CJD patient brains}

H-FABP protein expression was localized to neurons, astrocytes and endothelial cells. Typical neuropathological findings in CJD patients included spongiform changes, neuronal loss in cerebral cortex, and moderate microglial activation. H-FABP immunohistochemistry revealed three notable features: staining was stronger in neurons surrounding lesions than in those from tissue lacking pathogenic lesions; reactive astrocytes that surrounded spongiform changes were positive for H-FABP (Supplementary Figure 4); and the distribution of H-FABP expression was similar to abnormal prion protein expression distribution. We assumed that these characteristics of $\mathrm{H}-\mathrm{FABP}$ expression corresponded to direct or indirect protein-protein interactions between H-FABP and abnormal prion protein.

\section{Correlation between H-FABP ELISA and t-tau protein levels}

The Kendall and Spearman's coefficients of correlation between the protein levels of t-tau and H-FABP were 0.374 and 0.263 , respectively, revealing little correlation between the levels of t-tau protein and H-FABP as assessed by ELISA (Supplementary Figure 3-a).

\section{Correlation between H-FABP ELISA and S-100 protein levels}

The Kendall and Spearman's coefficients of correlation between the protein levels of t-tau and H-FABP were 0.424 and 0.389 , respectively, revealing little correlation 
between the levels of t-tau protein and H-FABP as assessed by ELISA (Supplementary Figure 3-b). 


\section{DISCUSSION}

The differential diagnosis of dementia is typically based on clinical criteria, while neurochemical data are rarely included in the diagnostic algorithms. In the case of sporadic CJD, WHO has included the detection of CSF 14-3-3 protein in the diagnostic criteria. However, 14-3-3 protein is not always the best diagnostic marker for CJD because the sensitivity of assays for 14-3-3 protein is lower than that of assays for t-tau protein. Therefore, there is a need for a new diagnostic marker for CJD reflecting both the neuronal loss in the disease, as 14-3-3 protein and t-tau protein do, and the activation of microglia as $\mathrm{S}-100$ protein does.

The aim of this study was to investigate whether a proper diagnosis could be made using a disease-specific spot pattern on a 2D-PAGE gel. Three protein spots that were previously reported by Cepek et al. (Cepek et al. 2007). were consistently and specifically expressed in the CSF of patients suffering from CJD. However, the present study focused on a single CJD-specific spot,which was identified as H-FABP (Fgiure1). Our study was not enough in comparison with Cepek et al. (Cepek et al. 2007) and Brechlin et al. 's researchs (Brechlin et al. 2008) because we were not able to detect 107 spots but their research were detected more than 2000 spots. We detected some spots (14-3-3 protein, NSE and LDH). So Cepek et al. (Cepek et al. 2007) research was detected H-FABP in same method, but Brechlin et al. (Brechlin et al. 2008) research was not detected H-FABP. We thought the reason was the depletion of protein or albumin in CSF at the step of pretreatment of 2D-PAGE.

Guillaume et al. (Guillaume et al. 2003) and Steinacker et al. (Steinacker et al. 2004) have previously reported that H-FABP detection could therefore be helpful as a screening test for a pre-mortem diagnosis of the disease, and also to prevent the risk of iatrogenic transmission of CJD, but the function of H-FABP was not identified. However, the numbers of CJD patients and patients with other causes of rapid progressive dementia in these studies were insufficient for the authors to draw a definitive conclusion. ELISA kits for measuring H-FABP, 14-3-3 protein, and t-tau protein in the CSF are sufficiently sensitive (Table 1 and 2-a), but some cases that were negative for t-tau protein and 14-3-3 protein were positive for H-FABP (Table 2-b); therefore, we speculate that the combination of t-tau protein and H-FABP would be good diagnostic markers for prion disease.

To prove its value as a diagnostic marker for CJD, it is necessary to show that changes in H-FABP levels are associated with neuronal loss and astrocytic gliosis. CJD patients in the early stage of disease present with mild and moderate neuronal loss; therefore, Satoh et al. (Satoh 2007b) identified that t-tau protein and 14-3-3 protein 
levels in the CSF of CJD patients in the early stage of disease were not useful. Atypical cases of sporadic CJD such as those with the MM2-cortical form or a V180I mutation causing familial CJD present with little neuronal loss and mild astrocytic gliosis. Therefore, there is a need for a biomarker reflecting both neuronal loss and mild astrocytic gliosis. H-FABP levels were not correlated with t-tau protein levels (Supplementary Figure 3-a). On the basis of neuropathologic and histologic examinations, t-tau expression was observed on the cytoskeletons of neurons, and t-tau protein levels detected by ELISA were correlated with neuronal loss. Changes in H-FABP levels did not always reflect only neuronal loss, because H-FABP ELISA concentrations did not correlate with t-tau protein concentrations (Spearman's rank correlation coefficient 0.263; Kendall's coefficient 0.374) (Supplementary Figure 3-a). H-FABP levels were not correlated with S-100 protein levels (Supplementary Figure $3-b)$. On the basis of neuropathologic and histologic examinations, S-100 protein expression was observed on astrocytes, and S-100 protein levels as detected by ELISA were correlated with astrocytic gliosis or activated astrocytes. H-FABP immunostaining was observed on neurons, activated astrocytes and endothelial cells; however, 14-3-3 and t-tau protein expression was visible only in neurons. In addition, high H-FABP concentrations were associated with a low t-tau protein levels. Neuropathological findings revealed that neurons and astrocytes expressed H-FABP; however, neuronal 14-3-3 and t-tau staining patterns differed from H-FABP staining characteristics.

Rapicheck ${ }^{\circledR}$ H-FABP analysis of CSF samples made up for the shortcomings of the ELISAs. Because the Rapicheck ${ }^{\circledR}$ H-FABP assay is a one-step immunochromatography method, it has the advantage of providing results within 15 minutes and allows for individual measurements of H-FABP levels. Therefore, costs were minimized and the risk of infection by abnormal prion proteins was reduced.

H-FABP levels might reflect disease stage: ELISA H-FABP has the possibility of being a chronological marker reflecting the time course of the clinical condition (Supplementary Figure 1-a,b). Moreover, CSF H-FABP is a useful diagnostic marker for atypical cases of CJD. The atypical cases of CJD that were negative for 14-3-3 protein and had low levels $(<1,300 \mathrm{pg} / \mathrm{ml}$; cut-off data) of t-tau protein were positive $(>3,200 \mathrm{pg} / \mathrm{ml}$; cut-off data) for H-FABP by ELISA (Table 2-a). The atypical cases of CJD had lower levels of t-tau protein, so the extent of neuronal loss in atypical cases of CJD was smaller than in typical and classical cases of CJD. H-FABP is therefore more useful as a diagnostic marker than 14-3-3 protein and t-tau protein in atypical cases of CJD. Collectively, our results show that H-FABP is a useful diagnostic marker in CJD patients. 


\section{REFERENCES}

Aguzzi A, Heikenwalder M (2006) Pathogenesis of prion diseases: current status and future outlook. Nat Rev Microbiol 4(10):765-75

Brandel JP, Delasnerie-Laupretre N, Laplanche JL et al. (2000) Delasnerie-Laupretre N, Laplanche JL et al. Diagnosis of Creutzfeldt-Jakob disease: effect of clinical criteria on incidence estimates. Neurology 54:1095-1099

Brechlin P, Jahn O, Steinacker P, Cepek L et al. (2008) Cerebrospinal fluid-optimized two-dimensional difference gel electrophoresis (2-D DIGE) facilitates the differential diagnosis of Creutzfeldt-Jakob disease. Proteomics 20:4357-4366.

Cepek L, Brechlin P, Steinacker P et al. (2007) Proteomic analysis of the cerebrospinal fluid of patients with Creutzfeldt-Jakob disease. Dementia and Geriatric Cognitive Disorders 23:22-28.

Collinge J, Gorham M, Hudson F et al. (2009) Safety and efficacy of quinacrine in human prion disease (PRION-1 study): a patient-preference trial. Lancet Neurology 8:334-344

Geschwind MD (2009) Clinical trials for prion disease: difficult challenges, but hope for the future. Lancet Neurology 8:304-306.

Guillaume E, Zimmermann C, Burkhard PR et al. (2003) A potential cerebrospinal fluid and plasmatic marker for the diagnosis of Creutzfeldt-Jakob disease. Proteomics 3:1495-1499.

Hiura M, Nakajima O, Mori T, Kitano K (2005) Performance of a semi-quantitative whole blood test for human heart-type fatty acid-binding protein (H-FABP). Clinical Biochemistry 38:948-950.

Laemmli UK (1970) Cleavage of structural proteins during the assembly of bacteriophage T4. Nature 227:680-685.

Mallucci G, Collinge J (2004) Update on Creutzfeldt-Jakob disease. Curr Opin Neurol 17(6):641-7

Orru CD, Wilham JM, Hughson AG et al. (2009) Human variant Creutzfeldt-Jakob disease and sheep scrapie PrP(res) detection using seeded conversion of recombinant prion protein. Protein Eng Des Sel 22:515-521

Owada Y, Yoshimoto T, Kondo H (1996) Spatio-temporally differential expression of genes for three members of fatty acid binding proteins in developing and mature rat brains. Journal of Chemical Neuroanatomy ;12:113-122.

Rabilloud T (1999) Silver staining of 2-D electrophoresis gels. In: Link AJ, ed. Methods in molecular biology. Totowa, NJ: Human Press 112:297-305. 
Satoh K, Shirabe S, Eguchi H et al. (2007a) Chronological changes in MRI and CSF biochemical markers in Creutzfeldt-Jakob disease patients. Dementia and Geriatric Cognitive Disorders 23:372-381-a

Satoh K, Shirabe S, Tsujino A et al. (2007b) Total tau protein in cerebrospinal fluid and diffusion-weighted MRI as an early diagnostic marker for Creutzfeldt-Jakob disease. Dementia and Geriatric Cognitive Disorders 24:207-212.

Satoh K, Tobiume M, Tsujino A et al. (2010) Establishment of a standard 14-3-3 protein assay of cerebrospinal fluid as a diagnostic tool for Creutzfeldt-Jakob disease. Laboratory Investigation, in press.

Steinacker P, Mollenhauer B, Bibl M et al. (2004) Heart fatty acid binding protein as a potential diagnostic marker for neurodegenerative diseases. Neuroscience Letters 370:36-39.

Watts JC, Balachandran A, Westaway D (2006) The expanding universe of prion diseases. PLoS Pathog 2(3):e26 


\section{ACKNOLEDGEMENTS}

We thank the members of the CJD Surveillance Committee in Japan. This work was supported by Grants-in-Aid of the Research Committee of Prion disease and Slow Virus Infection from the Ministry of Health, Labor and Welfare of Japan. 


\section{FIGURE LEGENDS}

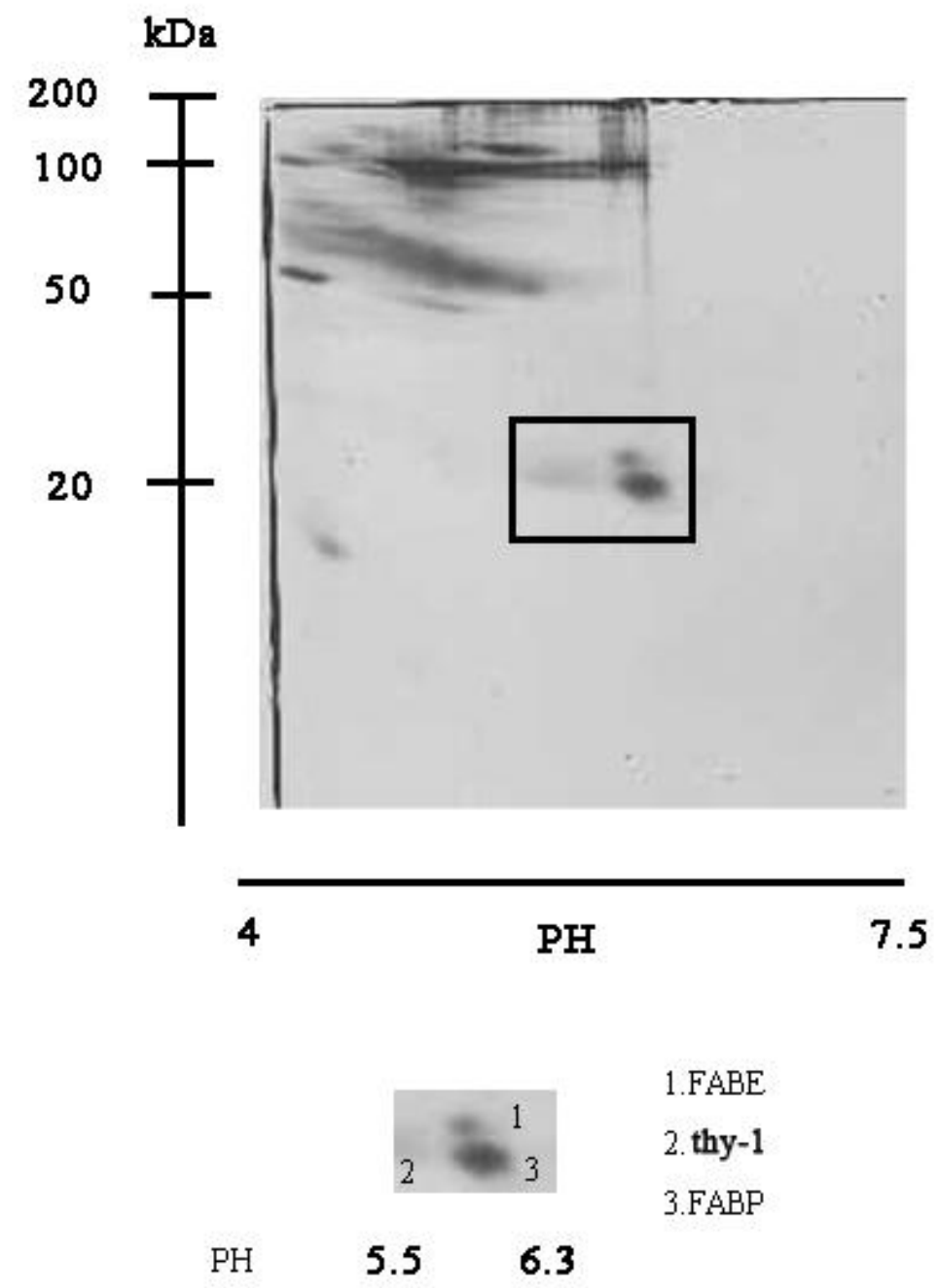

Figure 1

1-a. Silver-stained 2D-PAGE gel containing CSF proteins from CJD patients. Proteins were separated on the basis of size and charge.

1-b. Spots of higher intensity in CSF samples from CJD patients compared with CSF samples from healthy subjects. Thy-1 is transthyretin, so FABE and FABP represented epidermal fatty acid binding protein and fatty acid binding protein, respectively. 


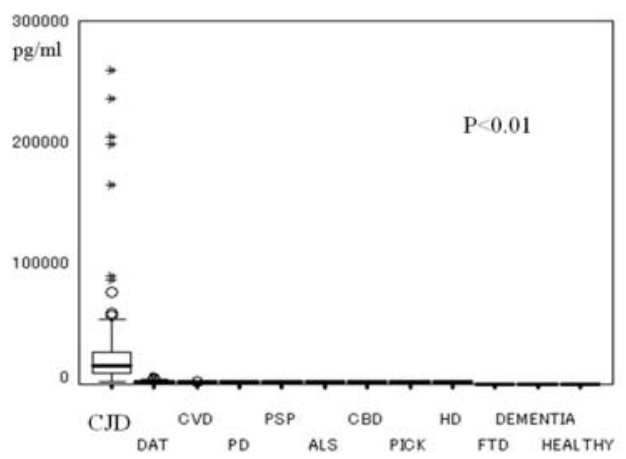

2-a

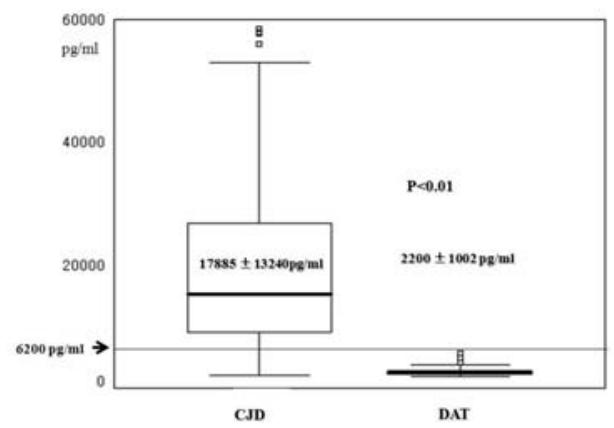

DAT

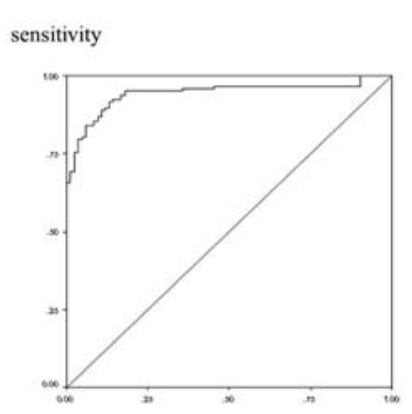

1- specificity
Figure 2 ELISA analysis of CSF from patients with CJD and other forms of dementia.

2-a. Results of ELISA analysis of CSF from patients with CJD and other forms of dementia.

CJD: Creutzfeldt-Jakob disease; DAT: dementia of Alzheimer's type; CVD: cerebrovascular disorders; PD:

Parkinson's disease; PSP: progressive supranuclear palsy; ALS: amyotrophic lateral sclerosis; CBD: corticobasal degeneration; PICK: Pick's disease; HD: Huntington's disease; FTD: frontotemporal dementia 2-b. Comparison of CJD patients and DAT patients.

2-c. Receiver operating curve characteristics at different cut-off points of CSF H-FABP concentration. 


\section{$\mathrm{pg} / \mathrm{ml}$}

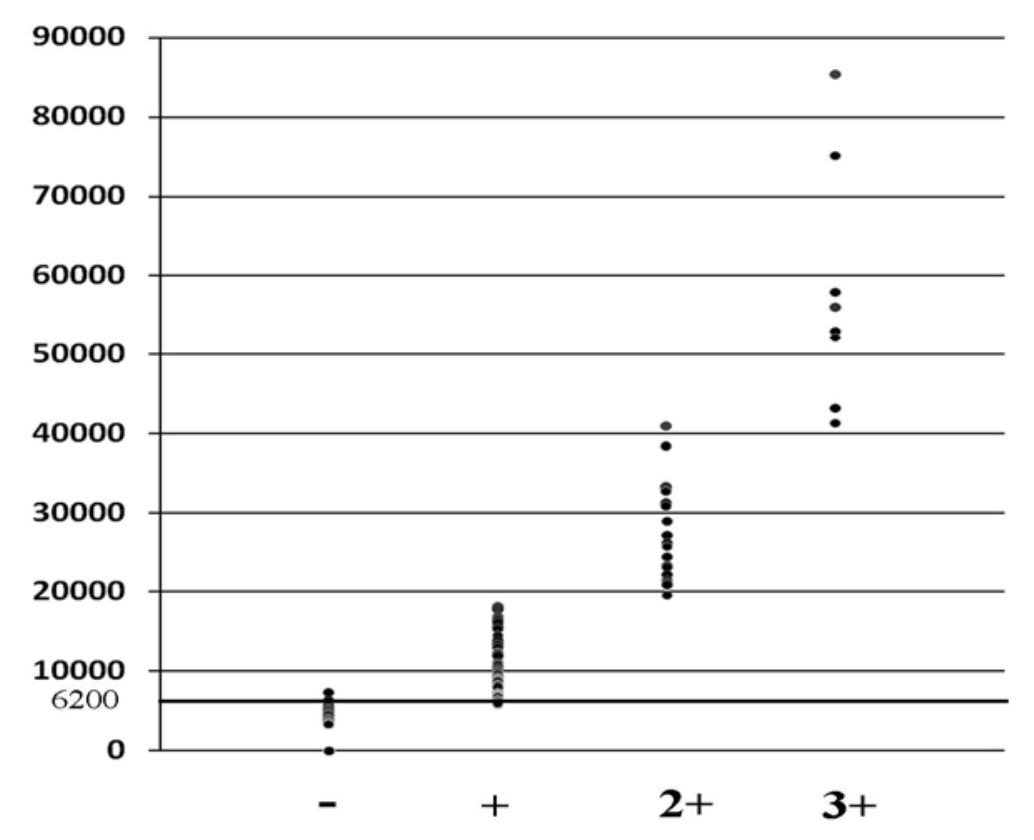

\begin{tabular}{|c|c|c|c|c|}
\hline & $\begin{array}{c}\text { negative } \\
\text { visual } \\
\text { reading }\end{array}$ & \multicolumn{3}{|c|}{ positive visual reading } \\
\cline { 2 - 5 } & - & + & $2+$ & $3+$ \\
\hline CSF H-FABP $>6.2 \mathrm{ng} / \mathrm{ml}$ & 10 & 72 & 20 & 8 \\
\hline CSF H-FABPH $<6.2 \mathrm{ng} / \mathrm{ml}$ & 13 & 3 & 0 & 0 \\
\hline
\end{tabular}

Figure 3 The relationships between H-FABP levels detected by ELISA and Rapicheck ${ }^{\circledR}$ H-FABP methods in the CSF of CJD patients.

The appearance of an indicator test line (in addition to the quality control line) within 5 minutes was graded +3 (strongly positive); appearance of a test line within 15 minutes was graded +2 (moderately positive); and the appearance of a weak test line within 15 minutes was graded +1 (weakly positive). The absence of a test line at 15 minutes was reported as 0 (negative) (Sup Figs1). We clarified the relationships between H-FABP levels detected by ELISA and Rapicheck ${ }^{\circledR}$ H-FABP methods in the CSF of CJD patients. Both methods showed similar levels, and we identified similar abilities to accurately measure CSF H-FABP levels in the range $0-86,000 \mathrm{pg} / \mathrm{ml}$. 


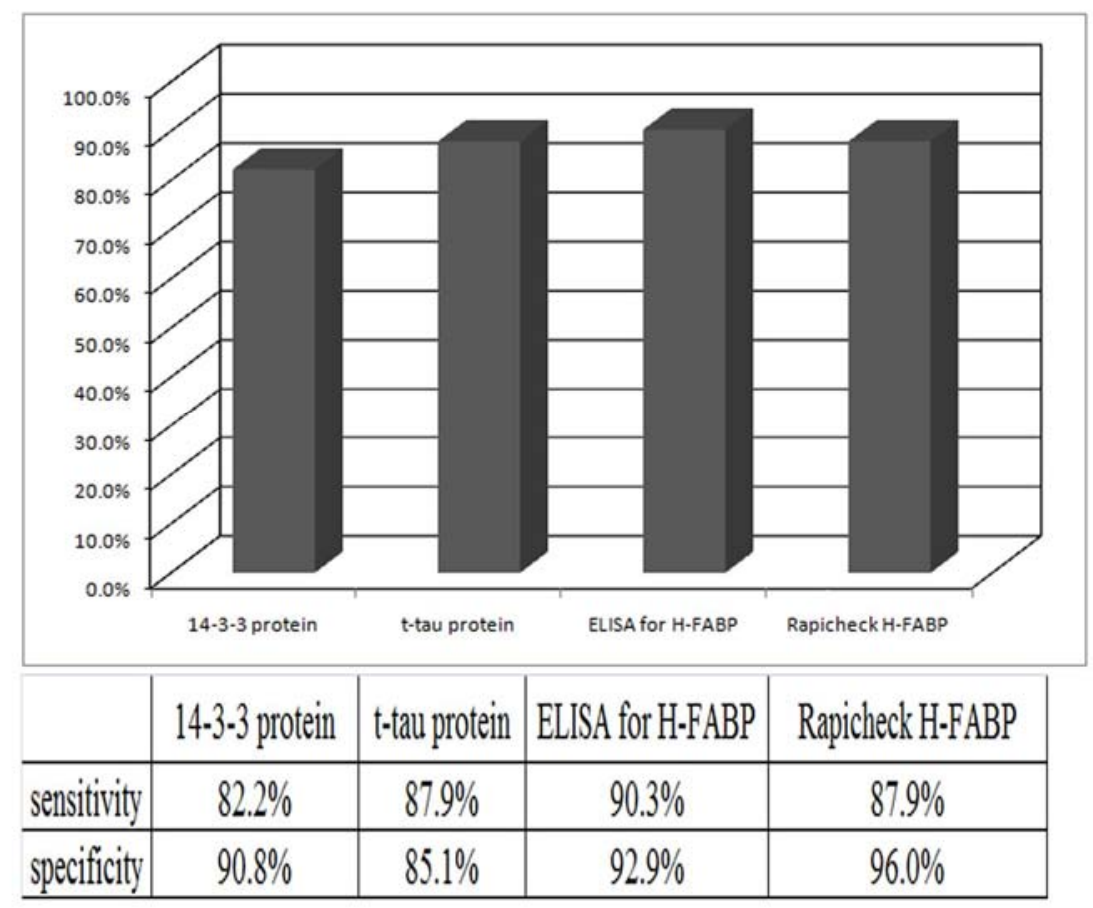

Figure 4 Correlation analysis of the positive CJD rate with 14-3-3 protein, total tau protein and S-100 protein using ELISA of H-FABP and Rapicheck ${ }^{\circledR}$ H-FABP methods 
ELISA of H-FABP $(\mathrm{pg} / \mathrm{ml})$

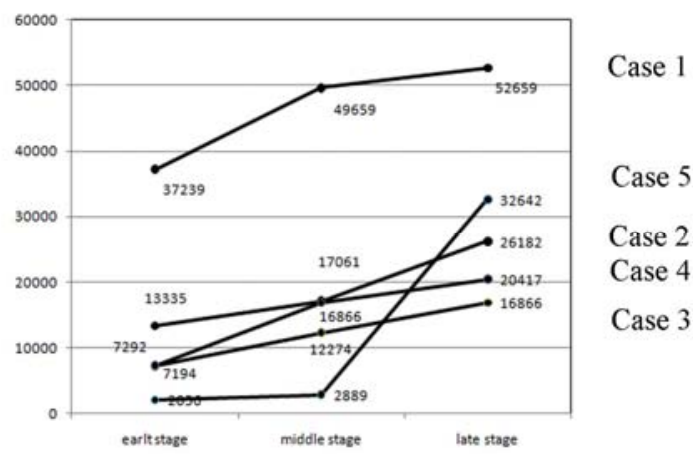

supplemenatry figute 1 -a

ELISA of H-FABP $(\mathrm{pg} / \mathrm{ml})$

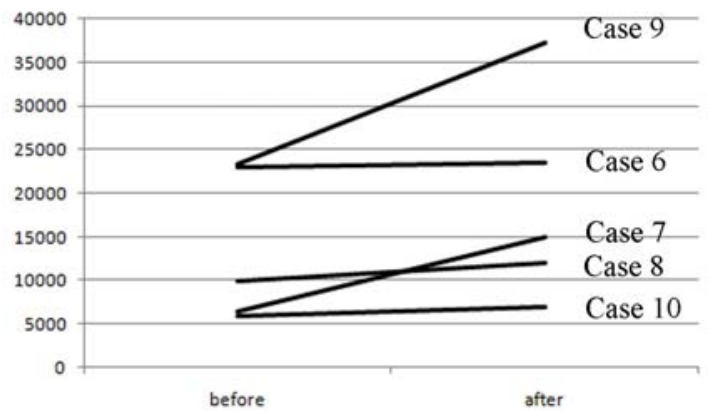

supplemenatry figute $1-b$

Supplementary Figure 1 Chronological changes in the ELISA for H-FABP results in CSF of CJD patients.

1-a. Chronological changes in H-FABP levels during the clinical course in the CSF of CJD patients, as detected by ELISA (cases 1-5); as reported by Satoh et al[14].

1-b. Comparative analysis of H-FABP levels in CSF as measured by ELISA before and after the onset of akinetic mutism (cases 6-10). 


\section{2-a}

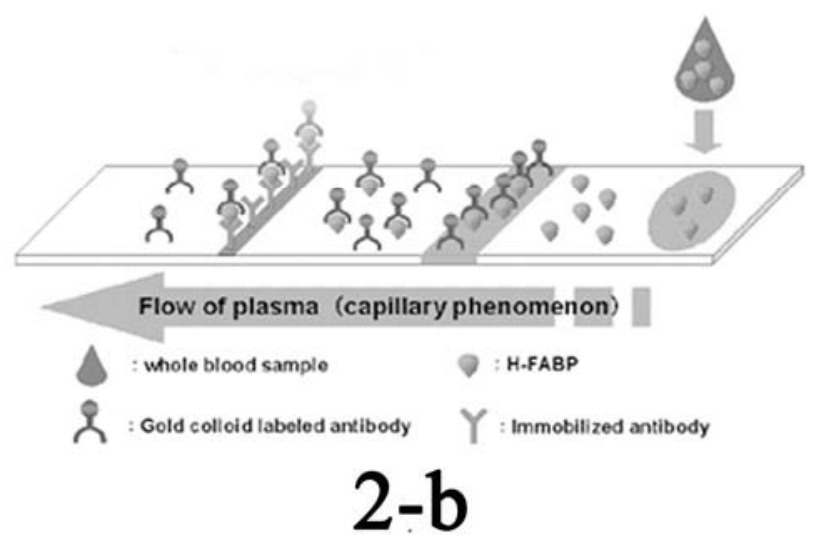

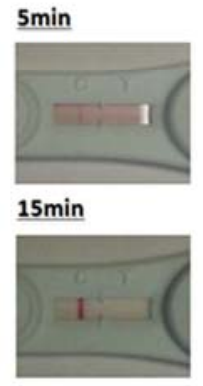

0
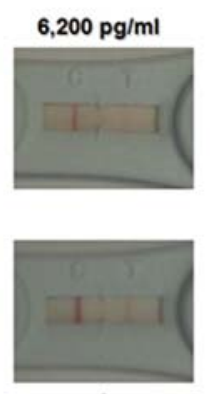

$+1$
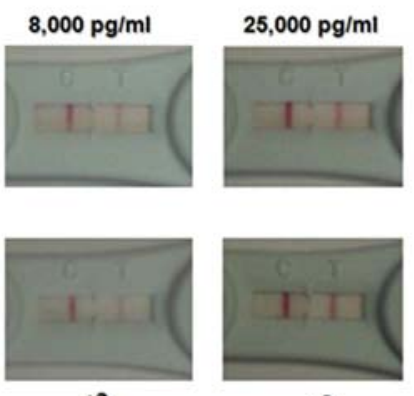

$+2$

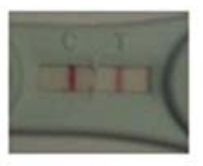

$+3$

Supplementary Figure 2 Rapicheck ${ }^{\circledR}$ H-FABP

2-a. Structure of the Rapicheck ${ }^{\circledR}$ H-FABP system.

2-b. Rapid semi-quantitative test for human H-FABP. The appearance of an indicator test line (in addition to the quality control line) within 5 minutes was graded +3

(strongly positive); appearance of a test line within 15 minutes was graded +2 (moderately positive); and the appearance of a weak test line within 15 minutes was graded +1 (weakly positive). The absence of a test line at 15 minutes was reported as 0 (negative). 


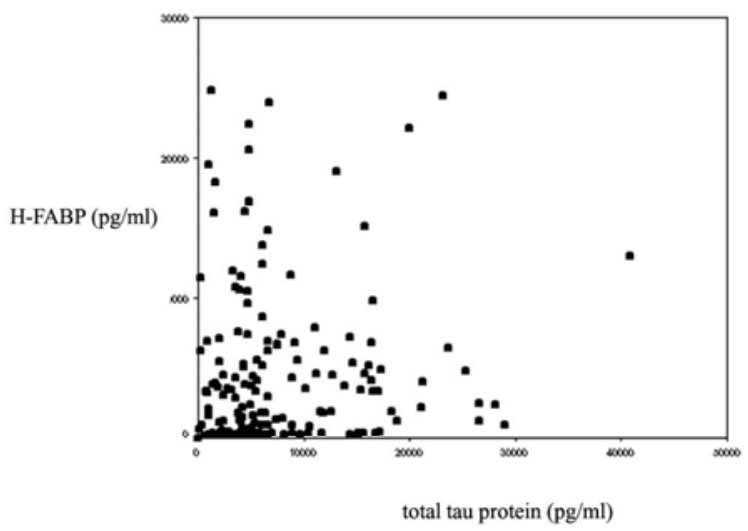

3-a

H-FABP (pg/ml)

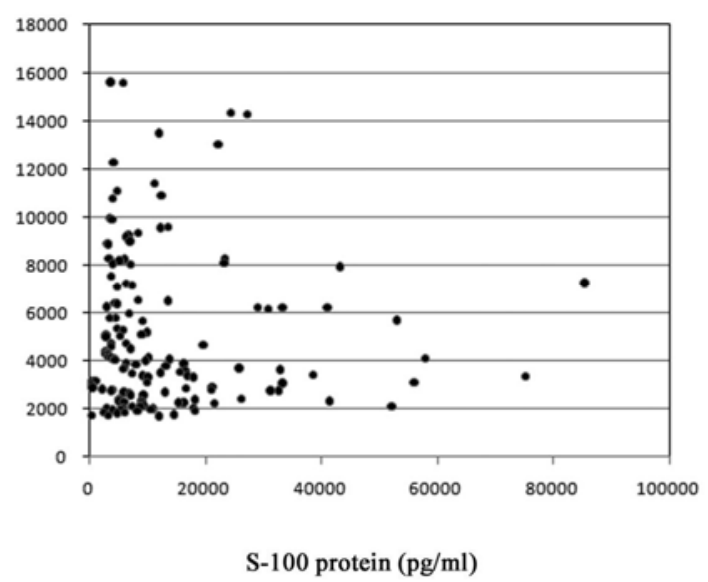

3-b

Supplementary Figure 3 Correlation analysis between H-FABP levels and either total tau protein or S-100 protein levels.

3-a. Correlation analysis between H-FABP and total tau protein levels.

3-b. Correlation analysis between H-FABP and S-100 protein levels. 

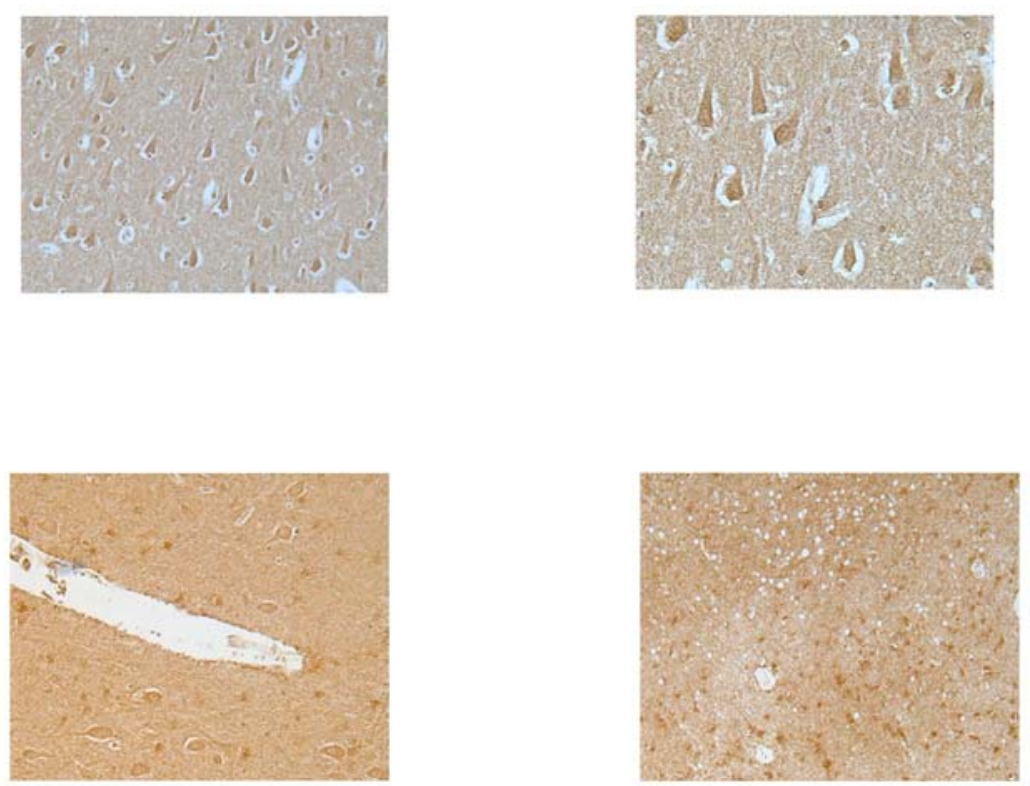

\section{Supplementary figure 4 \\ a b \\ c d}

Supplementary Figure 4 Neuropathology of H-FABP immunostaining in brain sections from CJD patients.

4-a. H-FABP immunostaining in brain sections from CJD patients.

4-b. Strong immunostaining of neurons surrounding the disease lesion.

There is a lot of neuronal loss in the cerebral cortex of CJD patients and

immunostaining of the surviving neurons in H-FABP, but H-FABP immunostaining is stronger in the lesion with an abundant accumulation of abnormal prion protein.

4-c. Reactive astrocytes surrounding spongiform changes were positive for H-FABP.

4-d. The distribution pattern of H-FABP matches that of abnormal prion protein. 
Table 1. CSF t-tau and H-FABP (ELISA) protein concentrations, and 14-3-3 protein expression analysis in 211 patients

$\begin{array}{ccccc}\text { diagnosis } & \begin{array}{c}\text { positive for } \\ 14-3-3 \text { protein }\end{array} & \begin{array}{c}\text { t-tau protein, } \\ \text { median }(\mathrm{pg} / \mathrm{ml}) \pm \mathrm{SD}\end{array} & \begin{array}{c}\text { H-FABP, } \\ \text { median }(\mathrm{pg} / \mathrm{ml}) \pm \mathrm{SD}\end{array} & \begin{array}{c}\text { The number of patients } \\ \text { of HFABP protein } \\ (>3,200 \mathrm{pg} / \mathrm{ml})\end{array} \\ \text { CJD } & 102 / 124 & 7174 \pm 6558 & 11,798 \pm 9,462 & 112 / 124 \\ \text { DAT } & 2 / 54 & 387.37 \pm 275.5 & 2,786 \pm 911 & 1 / 51 \\ \text { CVD } & 1 / 7 & 623.4 \pm 612.4 & 1,897 \pm 52.4 & 1 / 7 \\ \text { Pick's disease } & 0 / 1 & 267 \pm 100.4 & 1,614 & 0 / 1 \\ \text { PD } & 0 / 5 & 198.73 \pm 44.4 & 1,776 \pm 20.2 & 0 / 5 \\ \text { CBD } & 0 / 2 & 266.4 \pm 130.7 & 1,638 \pm 0 & 0 / 2 \\ \text { Huntington's disease } & 0 / 1 & 157 & 1,614 & 0 / 1 \\ \text { FTD } & 0 / 1 & 370 & 73 \pm 5 & 0 / 1 \\ \text { PSP } & 0 / 3 & 319.7 \pm 81.4 & 1,718 \pm 13.9 & 0 / 3 \\ \text { Wernicke's encephalopathy } & 2 / 2 & 1,910 \pm 106 & 7,850 \pm 205 & 2 / 2 \\ \text { limbic encephalitis } & 3 / 3 & 2,900.5 \pm 181.9 & 19,000 \pm 11.4 & 3 / 3 \\ \text { ALS } & 0 / 4 & 86.03 \pm 54.45 & 1,694 \pm 13.9 & 0 / 4 \\ \text { normal subjects } & 0 / 4 & 95.30 \pm 51.11 & 20 \pm 8.2 & 0 / 4\end{array}$

CJD: Creutzfeldt-Jakob disease; DAT: dementia of Alzheimer's type; CVD: cerebrovascular disorder; PD: Parkinson's disease; CBD: corticobasal degeneration FTD: frontotemporal dementia; PSP: progressive supranuclear palsy; ALS: amyotrophic lateral sclerosis 
Table 2. Biomarker presence in 112 patients with H-FABP-positive CSF $(>3,200 \mathrm{pg} / \mathrm{ml})$

Table 2-a. Analysis of biochemical markers (t-tau protein and 14-3-3 protein) in CSF

\begin{tabular}{|c|c|c|c|}
\hline \multicolumn{2}{|c|}{} & \multicolumn{2}{|c|}{ t-tau protein } \\
\cline { 3 - 4 } \multicolumn{2}{|c|}{} & Positive $(>1,300 \mathrm{pg} / \mathrm{ml})$ & Negative $(<1,300 \mathrm{pg} / \mathrm{ml})$ \\
\hline \multirow{3}{*}{$14-3-3$ protein } & positive & 99 cases & 4 cases \\
\cline { 2 - 4 } & negative & 4 cases & 5 cases \\
\hline
\end{tabular}

Table 2-b. Profiles of patients with H-FABP-positive CSF but negative for t-tau protein and 14-3-3 protein

\begin{tabular}{|c|c|c|c|c|c|c|c|c|c|}
\hline & \multirow[t]{2}{*}{ age } & \multirow[t]{2}{*}{$\operatorname{sex}$} & \multirow[t]{2}{*}{ classification } & \multirow{2}{*}{$\begin{array}{l}\text { Classification of } \\
\text { CJD on Parchi's } \\
\text { classification }\end{array}$} & \multicolumn{2}{|c|}{$\begin{array}{c}\text { Polymorphism in } \\
\text { PRNP }\end{array}$} & \multirow{2}{*}{$\begin{array}{l}14-3-3 \\
\text { protein }\end{array}$} & \multirow{2}{*}{$\begin{array}{l}\mathrm{t} \text {-tau } \\
\text { protein } \\
(\mathrm{pg} / \mathrm{ml})\end{array}$} & \multirow{2}{*}{$\begin{array}{l}\text { H-FABP } \\
(\mathrm{pg} / \mathrm{ml})\end{array}$} \\
\hline & & & & & 129 & 219 & & & \\
\hline 1 & 54 & $\mathrm{f}$ & sporadic case & $\begin{array}{l}\text { definite case } \\
\text { MM2 }\end{array}$ & $\mathrm{M} / \mathrm{M}$ & $\mathrm{E} / \mathrm{E}$ & negative & 1180 & 6458 \\
\hline 2 & 74 & $\mathrm{~m}$ & sporadic case & $\begin{array}{c}\text { definite case } \\
\text { MV2 }\end{array}$ & $\mathrm{M} / \mathrm{V}$ & $\mathrm{E} / \mathrm{E}$ & negative & 362 & 5260 \\
\hline 3 & 85 & $f$ & $\begin{array}{c}\text { familial case } \\
\text { V180I }\end{array}$ & probable case & $\mathrm{M} / \mathrm{M}$ & $\mathrm{E} / \mathrm{E}$ & negative & 1240 & 5333 \\
\hline 4 & 77 & $f$ & $\begin{array}{c}\text { familial case } \\
\text { V180I }\end{array}$ & probable case & $\mathrm{M} / \mathrm{M}$ & $\mathrm{E} / \mathrm{E}$ & negative & 468 & 5212 \\
\hline 5 & 71 & $\mathrm{~m}$ & $\begin{array}{c}\text { familial case } \\
\text { M232R }\end{array}$ & probable case & $\mathrm{M} / \mathrm{M}$ & $\mathrm{E} / \mathrm{E}$ & negative & 1100 & 8026 \\
\hline
\end{tabular}

